\title{
Leveraging Wireless Broadband to Improve Police Land Mobile Radio Programming: Estimating the Resource Impact
}

\author{
Jeremy G. Carter \\ School of Public and Environmental Affairs \\ Indiana University - Purdue University Indianapolis \\ carterjg@iupui.edu \\ Eric L. Piza \\ John Jay College of Criminal Justice \\ Department of Criminal Justice \\ epiza@jjay.cuny.edu \\ Eric Grommon \\ School of Public and Environmental Affairs \\ Indiana University - Purdue University Indianapolis \\ egrommon@iupui.edu
}

\begin{abstract}
Despite rapid growth in criminological studies of police technology, examinations of police land mobile radios are absent in the literature. This is troubling given the central role mobile radio serve in police operations and their significant management costs. The present study seeks to fill this gap by introducing the functionality of wireless broadband radio programming. Current practice requires a police officer to physically drive to a radio programming location to manage their mobile radio. Wireless programming remedies this burdensome reality, thereby saving officer time and cost. Geospatial analyses are used to estimate distance saved associated with wireless programming. We then conduct a number of calculations to determine time and cost savings related to the observed differences between existing and wireless radio programming within the context of the North Carolina State Highway Patrol. Results suggest wireless radio programming can save significant personnel and financial resources. Implications are discussed.
\end{abstract}

Keywords: Land mobile radios; Wireless broadband; Radio programming; Police technology; Geospatial estimates

\section{Funding:}

This research was supported by funding from the National Institute of Justice, U.S. Department of Justice. Grant Number 2010-IJ-CX-K023.

\section{Citation:}

Carter, J. G., Piza, E. L., \& Grommon, E. (2018). Leveraging wireless broadband to improve police land mobile radio programming: Estimating the resource impact. Journal of Crime and Justice. DOI: https://doi.org/10.1080/0735648X.2018.1554844

This is the author's manuscript of the article published in final edited form as:

Carter, J. G., Piza, E. L., \& Grommon, E. (2019). Leveraging wireless broadband to improve police land mobile radio programming: Estimating the resource impact. Journal of Crime and Justice, 42(1), 60-77. https://doi.org/10.1080/0735648X.2018.1554844 


\section{Introduction}

Land mobile radios are perhaps one of the most central types of police technology as they enable communication and coordination across officers and other necessary personnel. Despite the rapidly growing body of scholarly inquiry focused on police technology, mobile radios have largely gone ignored in the literature. This is troubling given the importance of this technology to police operations, vast government expenditures on radio communications, and significant cost and personnel time associated with radio communication maintenance and operations. A recent innovation in police land mobile radios has been the development of wireless-enabled mobile radios. In contrast to existing mobile radios, wireless-enabled radios are able to leverage over-theair-programming (OTAP) to complete repetitive programming tasks. This is a significant departure from current practice that relies upon a physical connection between a mobile radio and a computer, as well as the expertise of a trained radio programming technician. A forward-looking report from the National Institute of Justice (2009) asserted the use of OTAP should be a goal for public safety agencies because adoption of this technology should improve day-to-day operations and maintenance, reduce logistical and financial burdens associated with managing radios, and promote intra-system, intersystem and large-scale interoperability.

Through a partnership with the North Carolina State Highway Patrol (NCSHP), the present study seeks to quantify the potential impact of OTAP on police radio programming. It is assumed that wireless radio programming will generate substantial resource and time savings as compared to current radio programming methods. Geospatial analyses, combined with baseline time and cost measures from North Carolina, are leveraged to develop statistical models to inform estimates of time and cost savings associated with OTAP adoption as compared to legacy (current) radio programming. Findings of this study have implications for agencies considering the adoption of 
wireless radio programming as a tool to manage their communications systems and it offers a case study in empirically measuring important, but elusive, benefits that OTAP technology can provide police.

\section{Emerging Technology in Policing}

Technology is perhaps one of the most rapidly evolving aspects of contemporary policing. As technological leaps are made in society, innovative hardware and software are made more reliable with price points lowering to levels that make adoption within municipal organizations, such as the police, more viable. Technology is seen as a means through which organizations can achieve improved technical efficiency (Rutgers and van der Meer 2010) and outcome effectiveness (Hatry 2014). Indeed, police agencies across the United States have recently adopted a range of technologies with these end-goals in mind and technology acquisition is considered a top priority among police executives (Koper et al. 2009). Body-worn cameras, license plate readers, gunshot detection systems, smart devices, mobile broadband data access, and predictive crime mapping software are just a few of the innovative technologies police departments have begun to adopt in recent years.

Research has provided preliminary support for select efficiency and effectiveness gains in policing. In his review of body-worn camera evidence, White (2014) concluded this technology showed promise to improve both officer and citizen behaviors, improve citizen perceptions of police legitimacy, expedite resolutions to police complaints, and add evidentiary value to investigations. However, White (2014) also noted a number of concerns and unanswered questions surrounding body cameras related to privacy, resources, training, and policy development. Similar

sentiments were echoed by Lum et al. (2015) in their review of body camera studies, concluding that despite a massive growth of research on this technology, many studies lacked rigorous 
methodologies and tended to focus on similar outcomes. Their report concludes with a comprehensive list of areas in which further research is needed to appropriately assess body camera effectiveness and to thereby justify resources for procurement. This preliminary body-worn camera evidence captures the essence of other innovative policing technologies more generally. While studies have observed initial positive outcomes related to gunshot detection systems (Choi et al. 2014; Irvin-Erickson et al. 2017; Mares and Blackburn 2012), license plate readers (Koper et al. 2013; Lum et al. 2011; Taylor et al. 2012), mobile broadband data communications (Carter and Grommon 2014), and predictive policing software (Mohler et al. 2015), each one of these studies includes a discussion of noteworthy limitations, caveats to effectiveness, and urges scholars for future inquiries related to effectiveness.

This evidence shortcomings reflects a growing movement among criminologists calling for additional research on technology that moves beyond baseline assessments of engineering or process evaluations (Lum 2010a; Lum et al. 2010). In their multi-agency study to understand police technology adoption and effectiveness, Koper, Lum, and Willis $(2014,216)$ identify a salient weakness often attributed to police use of technology - that "police often fail to make strategically optimal uses of technology." Such a failure can be attributed to unrealistic expectations of technology performance and impact on outcomes, coupled with a disconnect between a technology deployment and traditional methods of police practice (Lum et al. 2017). Put simply, despite technology offering the capacity to improve the efficiency and/or effectiveness of police tasks, police often fail to change their methods of practice and operations to compliment technology performance. Two examples highlight this disconnect. First, great strides have been made in electronic reporting, crime mapping, and investigative tools, however crime clearance rates that rely on these improved capacities have yet to significantly change (Braga et al. 2011). 
Second, mobile data terminals in patrol vehicles enable more efficient reporting as compared to paper reports and citations, yet the time required for officers to complete reporting tasks has not decreased and can largely be attributed to the demand for additional information inputs within this updated system (Ioimo and Aronson 2004). In this latter example, it should be noted that other positive outcomes were achieved such as improved reliability of reporting and enhanced data querying, however the prime objective of improving reporting efficiency have not been readily observed.

\section{Knowledge Gap in Police Communication Technology}

Despite rapid growth among criminologists studying police technologies, and the fact that police radios have been in operation since the early 1930s, there is scant scholarly inquiry about the use of this technology in policing. Indeed, a review of relevant research yields not a single study from criminologists that examines operational capacity of mobile radios among police. While engineers from various disciplines have provided knowledge on technical components of mobile radios (Merwaday et al. 2016; Kumbhar et al. 2017; Sharp et al. 2004), criminologists have ignored this basic technology function. Mobile radios (or land mobile radios) serve a central function for police to carry out tasks that ensure coordination, safety, user-to-user communication, and effective response. This dearth of empirical evidence is troubling as it hinders informed decision making and stifles knowledge development within an important aspect of daily police operations.

It is timely that Blumstein (2018) recently authored an essay synthesizing research progress and gaps related to The Challenge of Crime in a Free Society (1967), or the U.S. President's Commission Report on Law Enforcement and Administration of Justice. Chapter 3 of this report's 
Task Force on Science and Technology specifically calls for evidence development on technology to impact police operations regarding "...information flow in police operations in terms of the communications networks, spectrum allocation, and the hardware needed to facilitate effective command and control through communications" (Blumstein 2018, 273). Land mobile radios are central to these police operations. Blumstein's (2018) conclusion was that many areas of the President's Commission Report suggestions about technology in policing have been ignored, and communications is arguably chief among these issues.

A contemporary need for research on police communication technologies is furthered by recent recommendations in The President's Task Force on 21 2 Century Policing (2015). Specifically, recommendation 3.7 calls for the federal government to prioritize the development and deployment of the First Responder Network (FirstNet), a national public safety broadband network exclusively for first responders. In addition to enabling access to broadband data communications, FirstNet also provides land mobile radio spectrum for improved coverage and enhanced interoperability. As the report notes (39), "FirstNet is considered a game-changing public safety project, which would allow instantaneous communication in even the most remote areas." While correct, this statement relies upon a more complex solution among mobile radio users that aims at the contribution of the present study. Effective radio communication through FirstNet relies upon 1) a radio technology that has wireless broadband programming capabilities, and 2) expected efficiency gains as a result of having wireless broadband-enabled mobile radios.

An unfortunate reality of police communications research is that such technology does not lend itself to rigorous evaluations. Communication technologies are extremely expensive, rely upon a large physical infrastructure and architecture (i.e., numerous mobile radios, signal towers, and dedicated spectrum), and are often vendor-specific thereby inhibiting the introduction of new 
or different components. These factors are not easily manipulated for experimental designs to assess effectiveness or efficiency gains. Thus, the present study incorporates a unique methodology of geo-estimates and extrapolated time and cost savings commonly used in other policing studies and applies these methods to existing police practice with mobile radios through a partnership with the North Carolina State Highway Patrol.

\section{Context of Land Mobile Radio Programming for Police: Legacy vs. Wireless}

Management and operations-focused tasks related to land mobile radios relies upon programmed "talk groups" within each radio device. In short, an officer is provided a mobile radio that is programmed to include certain persons with whom the officer may communicate. These talk groups are programmed into a mobile radio via code plugs - or a file that contains a list of channels on which certain users operate. For example, a patrol officer may have talk groups associated with his/her dispatch, patrol area, commanding officer, and other relevant personnel (such as investigations or historical checks). Thus, if an officer changes patrol area, is assigned to work a special event (such as a sporting event or large political gathering), or is responding to a natural disaster, he/she will require a new code plug to enable communications with relevant persons. Currently, police rely upon trained radio technicians and a physical cable connection to a computer to program a mobile radio. This is to say, when an officer needs their radio talk groups modified, they must physically provide their mobile radio to a technician who then physically attaches the radio to a computer, and then returns the radio to the officer. This process is antiquated, time consuming, and relies upon access to, and availability of, a radio technician.

A recent innovation in land mobile radios is over-the-air-programming (OTAP). Put simply, OTAP performs the programming task via wireless connection to some form of 
communications spectrum. For example, if an officer were assigned to work a special event the officer could download the appropriate code plug that includes the necessary talk groups for the event. Thus, OTAP enables officers to program their mobile radios on demand in the field, without having to take themselves out of service to physically provide their radio to a technician and wait for their radio to be returned. OTAP is not a new concept and is analogous to when cellular service providers "push" software updates to customer cell phones as a routine component of ongoing network maintenance and addition of new features. However, unlike these market segments, police land mobile radio systems function through the use of very narrow, Federal Communications Commission (FCC) defined, channel (spectrum frequency) allocations due to FCC narrowbanding requirements. Narrowbanding is an FCC mandated process intended to create more voice channel space within current land mobile spectrum allocations, leading to more efficient radio spectrum use (Federal Communications Commission 2006). As a result, the ability to perform OTAP within these narrow networks does not enable support of OTAP operations. Thus, OTAP is reliant upon a wireless connection to a mobile broadband network in order to have the requisite bandwidth to transfer code plugs.

OTAP also requires mobile radios to be software-defined, that is they rely upon software operations as opposed to firmware operations (firmware is analogous to an operating system on a personal computer). Currently the vast majority of public safety radios are software defined, as legacy firmware radios have been transitioned out (Federal Communications Commission 2018). A primary hurdle for OTAP and police radio programming is the issue of procuring mobile radio technology, specifically radio hardware, which is capable of connecting to a wireless network. A nationally recognized radio communications vendor recently developed a land mobile radio with built-in wireless connection capability. As part of a National Institute of Justice-funded project, 
the North Carolina State Highway Patrol was provided 30 wireless-enabled radios to test, evaluate, and provide proof of concept feedback. While the present study is not focused on the performance of this specific radio hardware, the research team was involved in the proof of concept deployment. Results indicated that the wireless-enabled land mobile radio could in fact connect to varying wireless broadband networks, and subsequently download code plug files wirelessly and quickly. As a result, this innovative land mobile radio technology has made OTAP an operational reality for police. To be clear, current practice in police operations involves the use of legacy, or physical attachment, radio programming methods. OTAP has yet to be adopted due to a number of systems architecture and proprietary issues. FirstNet is a primary step forward that will bring OTAP closer to an operational reality for many departments.

\section{Methods}

Study Site

This study was conducted in partnership with the North Carolina State Highway Patrol (NCSHP). This law enforcement agency embodies a number of characteristics from which the benefits of OTAP via wireless broadband technology can be examined, to include inter-agency interoperability, a large land mobile radio user community, and a geographically dispersed land mobile radio network. While NCSHP focuses on a range of citizen and legislative law enforcement and public safety issues, such as the supervision of prison offenders and preparation for natural disasters, the NCSHP focuses solely on the enforcement of laws on the state's roadways. More specifically, the NCSHP is responsible for traffic laws and efficient travel on more than 78,000 miles of roadway. In addition, the NCSHP serves as the primary state warning point, preparedness, and response agency for man-made and natural disasters. 
The North Carolina statewide radio system, Voice Interoperability Plan for Emergency Responders (VIPER), encompasses an area containing 100 counties. The VIPER system supports 90 unique radio zones, $700 / 800 \mathrm{MHz}$ conventional operation (analog and P25 digital), and both Motorola SmartNet and Project 25 trunked modes (depending on location). Not only is VIPER geographically extensive, it is also designed to support a large number of users. At the time of this study there were 65,388 active radios supported by the VIPER Network with plans to add an additional 10,000 radio users. This number of users requires the deployment and use of a large amount of mobile and portable radios, and therefore technical support. Managing a fleet of end user radios of this magnitude, to include both portable and mobile form factors, provides an opportunity to analyze and evaluate the potential impact of OTAP technology.

While radio compatibility is obviously a significant consideration for agencies; the subject of this effort is limited to the Wi-Fi technology created to demonstrate the feasibility of using broadband wireless technologies to facilitate OTAP and to explore the potential benefits of provisioning capabilities that are more efficient and effective than legacy radio provisioning tools. Management of a large land mobile radio fleet requires significant financial capital and human resources. Every radio in the VIPER system currently requires physical interaction with a radio technician to make routine or operationally changes. To make programming changes, portable and mobile radios must be transported by their assigned user to a designated service facility where a radio technician is available. This process impacts agency resources to include vehicle availability, vehicle wear and tear, fuel, trooper personnel time, and technician resources. Most importantly, these activities impact trooper availability to engage in service delivery. Thus, NCSHP radio operations provide an environment in which the potential benefits of OTAP can be explored. It should be noted that despite the large radio architecture of NCSHP, their radio programming 
operations are consistent with current national practice - thus the generalizability of findings to be presented are applicable to all police and public safety agencies in the country.

Data

In order to capture the organization of patrol services and radio programming activities, two datasets were obtained from the North Carolina State Highway Patrol (NCSHP). Both datasets are from 2015. The first was a GIS layer of the boundaries of each of the NCHP's eight Troops (Troop "A" through "H"). Troops are the organizational unit of the NCSHP, used to administer resource allocation and officer deployment throughout the state. For the purpose of patrol, officers assigned to a particular troop typically do not cross troop boundaries during their tours of duty. The second NCSHP dataset was the Radio Maintenance Sites. In total, the NCSHP operates eight Radio Maintenance Sites, one for each of the troops. When the need for radio programming arises, officers travel to the radio maintenance site within their troop. Addresses of the radio maintenance sites were provided by the NCSHP and confirmed through the website of the North Carolina Department of Public Safety ${ }^{1}$, and were then geocoded in the online batch geocoding tool of the Texas A\&M University's Geoservices Center. ${ }^{2}$ The NCSHP troop boundaries and radio maintenance sites, as well as major road types, are displayed in Figure 1.

\section{[ Insert Figure 1. North Carolina Highway Patrol Troop Boundaries, Radio Maintenance Site Locations, and Road Types approximately here ]}

\footnotetext{
${ }^{1} \mathrm{https}$ ///www.nccrimecontrol.org/Index2.cfm? $\mathrm{a}=000003,000014,001841,000745$

2 https://geoservices.tamu.edu/Services/Geocode/BatchProcess/
} 
Broadband Internet access across North Carolina was measured through data provided by NC Broadband, a division of the North Carolina Department of Commerce. ${ }^{3}$ NC Broadband maintains GIS data layers of broadband coverage throughout North Carolina as part of the National Broadband Map. ${ }^{4}$ As per their mission statement, NC Broadband collects data, and creates GIS maps of broadband coverage areas for public information purposes. Data is collected through a partnership with broadband providers, local governments, and North Carolina residents. Broadband coverage is categorized across nine separate spectrums. Each spectrum is associated with a specified type of broadband signal type, such as "Cellular," "Advanced Wireless Services," or "Satellite," for example. Within each spectrum, service providers report the range of speed they are able to provide. NC Broadband data includes 11 categories of speed ranges, from a low of less than or equal to 200 Kilobytes per second (kbps) and high of greater than or equal to one Gigabyte per second (gbps). Table 1 displays the minimum and maximum speeds available within each spectrum, as per the NC Broadband data.

\section{[ Insert Table 1. Wireless Broadband Services in North Carolina approximately here ]}

An important consideration for this study is the broadband speed necessary for OTAP to function. After several conversations with NCSHP engineers, it was concluded that the speed requirements should match the Federal Communications Commission's (FCC) minimum service speed classified as broadband, which at the time of this report was four Megabytes per second (mbps) downstream and one mbps upstream as defined by the FCC (2015). While precise speeds were not contained in the NC Broadband data, the FCC's minimum speed falls within the three

\footnotetext{
${ }^{3}$ http://www.ncbroadband.gov

${ }^{4}$ http://www.broadbandmap.gov/
} 
mbps to six mbps speed range captured by NC Broadband. Therefore, this range was considered the minimum needed to support OTAP. Each spectrum is associated with multiple speed ranges corresponding with the number of providers offering the signal type. Therefore, spectrums with a minimum download speed of three mbps to six mbps were considered as an appropriate and suitable location for network access via a Wi-Fi OTAP hot spot. This network speed is a conservative estimate to support OTAP functionality, as maximum speeds available in all but one of the spectrums exceeded current FCC standards. However, as a measure of minimum speed to support broadband OTAP functionality, our observations are limited to areas where OTAP is nearly guaranteed to function. As long as officer radios are able to connect to a Wi-Fi hot spot at an available broadband service in such areas, OTAP will operate.

According to this criterion, four of the nine broadband services identified in Table 1 have a sufficient minimum speed to support OTAP: spectrum two, spectrum five, spectrum eight, and spectrum nine. A spatial analysis of spectrum availability (not shown here for brevity, but available from the authors) revealed these four broadband spectrums to support OTAP covered virtually the entirety of North Carolina and thus the state has sufficient network coverage to support OTAP at broadband speeds. While spectrum five and spectrum eight only cover small pockets of the state, spectrums two and nine are present throughout North Carolina. Therefore, officers would likely be within, or very close, to an area with access to broadband speeds in excess of minimum, regardless of their deployment in North Carolina.

Officer travel distances were measured along roadways in North Carolina. Roadway data was obtained from two sources. First, researchers downloaded GIS shape-files of roads for each of North Carolina's 100 counties from the U.S. Census Website. ${ }^{5}$ The individual county files were

\footnotetext{
${ }^{5}$ http://www.census.gov/cgi-bin/geo/shapefiles2014/main
} 
then merged into a single layer. This Statewide Road dataset contained 550,024 roads throughout North Carolina. The census layer included the name and address range for each street. In order to obtain additional information for each road, specifically the road type (i.e. Local Road, Interstate Highway, etc.) a GIS layer was integrated with the North Carolina Department of Transportation's (NCDOT) road network, which was provided by the Institute for Transportation Research and Education (ITRE) at North Carolina State University. This dataset contained all of the roads maintained by the NCDOT $(\mathrm{N}=205,611)$. Roads in the NCDOT dataset were classified according to the following typologies: Interstate Highway, U.S. Highway, NC State Highway, and Secondary Roadway. A series of geo-processing techniques was conducted to integrate this information into the Statewide Road dataset. For each road category, a "select by location" function identified streets in the statewide dataset that were also within in the NCDOT file. Then, a dichotomous variable was created to categorize the street to the typology ("1") or not ("0"). This process was repeated four times, one for each of the DOT specified typologies. Any road in the Statewide Road dataset that did not overlap (and, thus, was not within) the DOT dataset was categorized as a "Local Road." In total, each road in the Statewide Road dataset was characterized according to one of the following road types: Interstate Roadway, U.S. Roadway, N.C. State Roadway, Secondary Roadway, or Local Roadway. These road types are illustrated in Figure 1 above.

\section{Analytical Approach}

\section{Trooper Location Calculation}

To review, the purpose of this analysis is to quantify the savings in officer driving mileage that a statewide OTAP implementation may provide over traditional radio programming. This required two location types to be operationalized: destinations where officers would drive to and origins where officers would drive from. As previously stated, the current study is interested in 
two alternate destinations: Radio Maintenance Sites and Wireless Broadband Access Points. Data provided to the research team allowed for direct measurement of the destinations. Officer origins were operationalized via a series of geo-processing steps in ArcGIS version 10.2.2.

Officer origins were operationalized in a manner that reflected NCSHP patrol practices. In particular, NCSHP has statewide jurisdiction, with officers actively patrolling roadways throughout North Carolina. NCSHP officials wished for the analysis to include all places where an officer may need to respond from. Since officers could hypothetically be in any area of the state when the need for radio programming arises, researchers first used the "create random points" tool of ArcGIS to generate a point on each of the 550,024 roads contained within the North Carolina Road database. In recognition of the varying length of roads, additional points were placed on longer roads, when necessary. The average and standard deviation of road lengths were used to determine the number of points to place on each road. Roads averaged 2,338.89 feet in length with a standard deviation of 6,152.62 feet, as measured within ArcGIS. An additional point (for a total of two points) was generated on roads greater than one standard deviation above the mean $(8,491.51$ feet). Above this threshold, additional points were created for every 2,338.89 feet in length. For example, a road 10,830.40 feet long ( 1 standard deviation above the mean $+2,338.89$ ) resulted in the creation of three officer origin points. ${ }^{6}$

In total, 645,640 origin points were created for this study. Figure 2 displays the officer origin points within a concise area of North Carolina. It should be noted that since the standard deviation is larger than the mean, the mean might not be the most appropriate measure of central tendency in this case. However, using the median length (865.35 feet) to determine point creation resulted in over 1.5 million points. This exceeded the number of points that could be exported into

\footnotetext{
${ }^{6}$ In ArcGIS the minimum distance between points per road was set to 2,338.89 feet to ensure that points attributed to the same road did not fall too close together.
} 
a spreadsheet from ArcGIS, which was needed to import the data into a statistical software package. This technological limitation required us to use the mean to guide origin point creation. Nevertheless, officer origin points appeared on every road in North Carolina, covering the entirety of the state. This allowed for rigorous exploration of the research question.

[ Insert Figure 2. Officer Origin Points approximately here ]

\section{Distance Calculation}

Following the creation of officer origin points, three distance variables were created. The first variable, Miles to Radio measured the mileage between each origin point and the Radio Maintenance Site of the encompassing Troop. The second variable, Miles to Broadband measured the mileage between each origin point and the nearest sufficiently strong Broadband coverage area (spectrum 2, spectrum 5, spectrum 8, and spectrum 9). The OD Cost Matrix Analysis tool in ArcGIS's Network Analyst extension was used to generate both of these distance variables. This tool measures the least-cost path in terms of driving distance along a street network from origin points to destination points. Following the creation of these distance variables, a Miles Saved variable was created. This variable was calculated by subtracting the Miles to Broadband value from the Miles to Radio variable. For example, if an origin point were 3.0 miles from a radio maintenance facility and 0.5 miles from a broadband access point, then the Miles Saved value would be 2.5 miles. The Miles Saved variable reflects the potential mileage savings that access to OTAP could offer the NCSHP. The central tendency of this variable provides a measure of the statewide benefit of OTAP may offer. To determine whether the mileage savings would be equally beneficial in subsections of the state, a series of mean difference tests were conducted. The first model tested whether the average Miles Saved significantly differed across the eight NCSHP 
troops. This model can help inform whether specific troops would experience greater benefits from OTAP than others.

A second model was conducted in recognition that NCSHP officers patrol a wide array of road types throughout the state. This model tested whether mean miles saved differed across the five road typologies in North Carolina: Interstate Highway, U.S. Highway, NC State Roadway, Secondary Roadway, and Local Roadway. Since different patrol functions (i.e. speed traps, road safety checkpoints, prisoner transport, etc.) are likely to occur on different types of roads, this model can help inform whether personnel involved in specific assignments would more greatly benefit from OTAP than others. Finally, five road-specific models were conducted to measure whether Miles Saved from origin points on a given road type significantly differed across Troops. These models combined the insights of the aforementioned models.

Analyses were conducted using STATA (v13.0). Mean differences were tested through a one-way analysis of variance (ANOVA) technique. ANOVA rests on the assumption that the variance in the dependent variable is equal across groups. To test this homogeneity of variance assumption, a Bartlett's $X^{2}$ test was conducted (Hamilton 2013, 151). When Bartlett's test achieves statistical significance, the homogeneity of variance assumption is violated. However, the ANOVA method is relatively robust to modeling violations, especially in the case of large samples. Nonetheless, when the Bartlett's test rejected the null hypothesis of equal variances, differences were measured in the dependent variable via a Kruskal-Wallis test, the nonparametric version of ANOVA. Kruskal-Wallis treats the dependent variable as an ordinal, rather than continuous, measure and reports the mean rank (rather than the mean value) for each group. This makes the Kruskal-Wallis test immune to any heterogeneity of variance within the dependent variable. This adds to the robustness of the analysis by ensuring that the ANOVA and Kruskal-Wallis findings 
are in agreement, thus rendering the ANOVA violations moot. Lastly, as a measure of the magnitude of Miles Saved across groups, the effect size of the mean differences is reported. Effect size values allow for the interpretation of the magnitude of the mean differences across groups, in addition to their statistical significance. The ETA ${ }^{2}$ statistic is reported, which is interpreted as the percent of the dependent variable accounted for by the effect in the sample. The magnitude associated with $\mathrm{ETA}^{2}$ values is as follows: 0.01 small effect; 0.06 medium effect; 0.14 large effect (Kirk 1995; Thompson 2006).

\section{Time Savings and Cost Savings Calculations}

Though officer time is considered a fixed cost as officers are paid regardless of their activities while on duty (Greasley and Smith 2017), time savings can translate into efficiency and effectiveness gains. Officers that spend less time responding to calls for service (White and Katz 2013) or completing administrative tasks (Lauria 2007) can reallocate that time to different, perhaps more mission-centric, activities. In the context of the present study, time savings for reallocated tasking can be achieved through reduced travel time for radio programming. To best estimate realistic travel time savings for NCSHP troopers, travel time was calculated using Google Maps Application Programming Interface (API) as the Google Maps API accounts for real-time traffic patterns, varying speed limits, and diverse terrain thereby accurately reflecting actual origin to destination travel times and distances (Wang and $\mathrm{Xu}$ 2011; Zhang et al. 2017). Travel time estimates were calculated within each NCSHP troop based upon the distance between each station location within each troop to the designated radio programming location for a given troop. For example, Troop A has 20 stations within the troop and travel time estimates were calculated from each of these 20 stations to the designated radio programming location. Travel time in minutes 
was calculated by dividing the travel time by distance traveled. Travel times were then averaged within each troop to determine a baseline travel time rate for each troop. This process was repeated for each of the eight troops. Travel times, in minutes per mile, ranged from 1.20 (Troops $\mathrm{G}$ and $\mathrm{H}$ ) to 1.38 (Troop F). These estimates mirror the national per-mile travel estimate rate of 1.27 on state roadways (U.S. Department of Transportation, 2015). It should be noted that Google Maps API outputs the most efficient travel route and time, thus estimates leveraged in the present study are conservative when attempting to determine time savings.

Beyond the potential to improve portable radio programming efficiency, OTAP may also help to alleviate some of the financial burden facing public safety budgets. At present, making programming changes to portable radios in preparation for an event, in response to an incident, and especially for day-to-day operations requires police and other first responders to drive to the closest and most appropriate service point to receive radio programming services. Such efforts are subject to personnel time and vehicle usage.

A common method of estimating costs of officer time is to extrapolate time effects across officer salary (Lauria 2007; White and Katz 2013). Trooper salary data was collected from the U.S. Bureau of Labor Statistics (2015). Hourly rates and subsequent minute rates were determined based on the 2,087-hour a year work schedule as defined by the 2015 U.S. Office of Personnel Management. The average NCSHP trooper salary was $\$ 61,200$ (which includes $36 \%$ for fringe benefits), which in turn translates to $\$ 29.32$ an hour and $\$ .489$ per minute. Driving costs are calculated based on the 2015 General Services Administration (GSA) rate of fifty-seven and a half cents (\$.575) per mile for personal vehicle use. This rate accounts for maintenance and vehicle usage (i.e., fuel consumption, vehicle maintenance, and depreciation costs). Resources related to training of radio technicians and trooper personnel as well as hardware procurement are not 
incorporated into the present analysis as the intent is to explore the operational potential of OTAP. Training and hardware procurement will remain constants across public safety regardless of technology and while the transition to new hardware would be costly, such costs are likely to occur over time regardless. To determine time and cost savings, the time and cost estimates described here are subsequently extrapolated across the aforementioned Miles Saved calculation. In their report published by the Urban Institute, Schaenman and Horvath (2013) identified a number of mechanisms that would allow police agencies could achieve cost savings through reduced fuel consumption. Their study specifically noted the use of available technologies as both a primary impact and side effect to reduce fuel cost. Technology advancements are one of the few avenues through which driving time and distance can be reduced while not reducing the quality of service or intended operation.

\section{Results}

\section{Travel Distance}

Table 2 displays descriptive statistics for the three distance variables: Miles to Radio, Miles to Broadband, and Miles Saved. As per the Miles to Radio values, officer origin points on average were a 35.69 mile drive from the Radio Maintenance Site, with a median of 33.57 miles and a standard deviation of 20.52 miles. Not surprisingly, the distance to the nearest Broadband Access Point was much closer. Virtually the entire state of NC falls within a coverage area of a sufficiently strong Broadband signal. Consequently, the Miles to Broadband values were minimal, with a mean and median of less than 0.01 of a mile and a standard deviation of only 0.001 of a mile. In fact, only 23 of the 645,640 observations had a Miles to Broadband value greater than 0.01 . Officers would have to travel a very minimal distance, if at all, from their origin points in order to use 
OTAP. As a result, the Miles Saved variable largely reflects the Miles to Radio values, with a mean of 35.68 miles, a median of 33.57 miles, and a standard deviation of 20.52 miles.

[ Insert Table 2. Summary of Distance Variables approximately here ]

Tables 5-6 display the results of the mean difference tests. Results of ANOVA were statistically significant in each model, rejecting the null hypothesis that Miles Saved averages were equal across groups. In each test, the Bartlett's $\mathrm{X}^{2}$ was significant, rejecting the null hypothesis of equal variance. Therefore, Kruskal-Wallis tests were conducted to verify the ANOVA results. In each model, the Kruskal-Wallis tests achieved statistical significance, adding further support for the finding that the potential Miles Saved offered by OTAP was not consistent across sub areas of North Carolina. Since statistical significance was achieved in each instance, the effect sizes provide a means to further compare the findings across models.

Table 3 reports the findings of the "Troops" model. In this model, the mean Miles Saved ranged from a low of 27.06 (Troop D) to a high of 46.70 (Troop A). The $\operatorname{ETA}^{2}(0.07)$ suggests a medium effect size. This contrasts with the "Road Types" model (see Table 4) with the ETA ${ }^{2}$ value of 0.002 suggesting a minimal effect size. However, while Road Type on a whole did not exhibit a strong influence on Miles Saved, origin points within specific road types did experience sizable differences across troops. Miles saved from origin points on Interstate Highways ranged from a low of 17.92 (Troop G) to a high of 38.89 (Troop B). The ETA ${ }^{2}$ of 0.20 suggests a large effect size (see Table 5). Observed $\mathrm{ETA}^{2}$ values were smaller for each of the other Road Types, though a medium effect size was exhibited in each case. For origin points on U.S. Highways and N.C. State Roadways, ETA $^{2}=0.05$. For origin points on U.S. Highways, Miles Saved ranged from a low of 29.96 (Troop F) to a high of 44.72 (Troop H). A range from 29.16 (Troop D) to 43.17 (Troop A) was observed for origin points on N.C. State Roadways. For origin points on Secondary Roadways 
and Local Roadway, $\mathrm{ETA}^{2}=0.08$. Ranges from 26.70 (Troop D) to 44.75 (Troop A) and from 27.14 (Troop D) to 48.10 (Troop A) were observed for origin points on Secondary Roadways and Local Roadways, respectively (see Table 5).

[ Insert Table 3. Average Miles saved across Troops approximately here ] [ Insert Table 4. Average Miles saved across Road Types approximately here ] [ Insert Table 5. Average Miles saved across Troops, by Road Type approximately here ]

\section{Time and Cost Savings}

Estimates for time and cost savings were calculated using the aforementioned baseline measures for travel distance, travel time, trooper salary, and vehicle usage. The number of troopers includes all sworn personnel assigned to the given troop, inclusive of all ranks (troopers, sergeants, lieutenants, captains, majors, and so forth). All personnel within the rank structure require radio communications and are subject to radio programming needs. These baseline costs were then extrapolated across the observed distance traveled savings achieved via OTAP generated through the geospatial estimates (the average miles saved across troops presented in Table 3). Focus groups between the research team and NCSHP, in addition to a review of radio technician work load, revealed that NCSHP troopers required their mobile radio to be programmed at least twice during a calendar year (with some troopers requiring many additional programming services depending on assignment). As a result these calculations are based on the minimum of two programming needs per year to reflect a conservative estimate of trooper mobile programming. These costs are also calculated based upon the number of troopers assigned within each troop area.

As an example of time and cost savings calculations, Troop A has 190 troopers assigned to this area and saved an average of 46.7 miles per radio programming need (as determined in the 
geospatial estimates). Troopers in Troop A travel at an average speed of 1.26 minutes per mile. Thus, total miles saved for Troop A is 17,746 (190 troopers*46.7 miles saved*2 programming trips). Total time saved for Troop A is 22,359.96 minutes (190 troopers*58.84 minutes (which is 46.7 miles*1.26 minutes per mile) saved*2 programming trips). Personnel cost savings for Troop A is $\$ 10,934.02$ (190 troopers*58.84 minutes saved*.489 per-minute salary rate*2 programming trips). Lastly, vehicle cost savings for Troop A is $\$ 10,203.95$ (190 troopers*46.7 miles saved*.575 cents per mile vehicle usage rate*2 programming trips). Total money saved for Troop A is $\$ 21,137.97$ ( $\$ 10,934.02$ personnel cost savings $+\$ 10,203.95$ vehicle cost savings).

Estimated time and cost savings are reported in Table 6. Similar to large municipal police agencies, NCSHP allocates resources to each troop to support operations and management; akin to each troop being its own police force. Estimates suggest Troop B may benefit most from OTAP adoption as it has the most troopers (256) and estimates to save the second most miles traveled for each programming need (42.39). Thus the total miles (21,703.68 miles) time (29.734.04 minutes) saved is substantial, as are the corresponding personnel $(\$ 14,439.95)$ and vehicle usage $(\$ 12,479.62)$ savings for a total cost savings of $\$ 27,019.56$ per year using OTAP as compared to existing mobile radio programming. In sum, OTAP of land mobile radios in the deployment context of the NCSHP could save a total of 119,252.34 miles driven, 150,554.70 minutes spent driving, $\$ 73,621.25$ in personnel time cost, $\$ 68,570.10$ in vehicle usage cost, and $\$ 142,191.34$ a year. To reiterate, this operational costs are conservative and reflect routine programming needs in a given year - this true time and cost savings are likely exacerbated when staffing large events, responding to disasters, and additional trooper programming needs are warranted.

[ Insert Table 6. Average Time and Cost Savings by NCSHP Troop approximately here ] 


\section{Discussion}

This study sought to quantify the potential benefits of implementing the OTAP radio programming method in North Carolina. Programming a radio while an officer is deployed in the field is less time and resource consuming than the officer driving to a centralized radio maintenance site. This much is obvious; statistical analysis was not needed to confirm this fact. What the analysis did provide was a means of further contextualizing such benefits. The findings suggest that OTAP may provide the NCSHP with significant savings in terms of miles driven for radio programming. The mean value of the Miles Saved variable suggests that implementing OTAP statewide may be a worthwhile investment. However, if budget constraints and related expenditures would not allow for state-wide implementation, then the NCSHP could maximize its investment by limiting deployment to the Troops and/or personnel that would benefit most from the technology. For example, OTAP can conceivably be provided exclusively to officers within Troops with the largest Miles Saved averages. In such a situation, Troop A (46.70), Troop B (42.39) and Troop H (36.97) exhibited the largest Miles Saved values and should be the first Troops considered for OTAP. While the overall Road Type model exhibited a minimal effect size, the results of the disaggregate Road Type models exhibited medium to large effects, and could be consulted to further refine OTAP deployment. For example, in regards to Troop A, the average Miles Saved values was greatest in the Local Roadways (48.10) and Secondary Roadways (44.75) models. Therefore, within Troop A, OTAP can only be provided to officers primarily deployed on Secondary and Local Roadways to maximize benefit. Conversely, for Troop H, the average Miles Saved was greatest on U.S Highways (44.72), suggesting that officers on such roadways have the most to gain from OTAP within this Troop. 
Potential resource impacts, in the forms of miles, time, and cost savings, are notable. In a given year, the NCSHP could eliminate troopers from having to drive 119,252.34 miles, for a total of $150,554.70$ minutes to have their mobile radio programmed. These time and effort savings translate to $\$ 73,621.25$ saved in personnel time and $\$ 68,570.10$ in vehicle usage costs, for a total of $\$ 142,191.34$ in a given year. These demonstrable resource impacts are noteworthy is these are two of the prime catalysts police executives expect when adopting new technology (Koper et al., 2009). Importantly, time and cost savings should not be considered as true "savings" in this context as officer time is a fixed cost. Rather, time and cost savings reported here help to quantify opportunity cost savings. Time and money spent on existing radio programming methods could translate into more time allocated towards mission-centric police services, such as time spent on patrol, if OTAP were adopted. It should also be note that troopers are not engaged in patrol duties during the time they travel for radio programming. Thus, these time and travel costs could be deployed more effectively.

Analyses presented here also do not account for the potential of OTAP to make preparation for, and response to, large events and disasters more effective and efficient. In such situations, troopers are required to have their radio programmed prior to arriving on scene at an event or disaster. Though less critical for large planned events, existing radio programming methods greatly inhibit response time to, and coordination during, a disaster or emergency situation. Under current methods, a trooper would have to physically meet a radio technician to have their mobile radio programmed for the situation at hand. Conversely, OTAP would allow a trooper to directly proceed to a situation while downloading a code plug file on the move, thus arriving on scene with ready communications and in a timelier manner. Such value is difficult to quantify, but the pragmatic benefits of OTAP during an emergency situation are not difficult to envision. Demand for this 
wireless programming capability of land mobile radios is articulated by the U.S. Department of Homeland Security (2014) (SAFECOM program) and the National Governors Association (2009, 9) that encouraged "the use of interoperable communications on a routine basis as the use of interoperable systems can build the capacity of end users to effectively use new equipment and strategies during an emergency" and that existing physical connection programming of land mobiles radios "... will be cumbersome and inhibit a coordinated response."

Lastly, technology adoption in policing has been plagued by a lack of optimal strategic use (Koper et al. 2014; Lum et al. 2017). This observation is consistent with the idea of tasktechnology fit (Ioimo and Aronson 2004) wherein technology adoption is most effective when technology can be expected to produce improvements related to a specific task within a specific organizational context. Given the importance of mobile radios to police operations, and the defined tasks radio enable (user communication), police agencies seeking to adopt OTAP are likely to avoid this potential pitfall. Once implemented, OTAP technology is also positioned to have an immediate impact on operations - thus allowing police executives and end-users to observe technology impact more quickly and develop personnel buy-in to the change (Zhao et al. 2003).

\section{Limitations}

Despite these implications, this research, like most others, has specific limitations that should be mentioned. For one, the manner by which the broadband data was collected prevented us from identifying places that may have weaker signal strength than the aggregate coverage areas. As noted, two of the four Spectrums with minimum speeds needed for OTAP extended throughout the state. However, it is reasonable to believe that the performance of said Spectrums was not homogenous across North Carolina. There are likely specific regions/neighborhoods/city blocks 
where signal strength is not as advertised, or where service interruptions occur more frequently than normal. The aggregation of the broadband data prevented us from identifying such areas. Therefore, the true "Miles to Broadband" values are likely higher for an unknown subset of officer origin points than what is reflected in this study.

Regarding the creation of the units of analysis, origin points were created for each individual street in North Carolina. This was in recognition of the statewide jurisdiction of the NCHP, and the desire of NCHP officials for the analysis to include all places in the state where an officer may be located. However, it is likely that NCHP officers do not spend an equal amount of time patrolling each road type. In addition, there may be specific roads in the state where the NCHP officers spend little to no time patrolling. The analysis would have benefitted from weighting observations so that origin points on roads more frequently patrolled by NCHP were more influential in the analysis. Unfortunately, the necessary data to measure patrol dosage was not available. Future research should attempt to overcome this limitation by using patrol data to better understand the patrol patterns, dosages, and frequency across a jurisdiction. One option would be to use automated vehicle locator (AVL) data to precisely measure patrol heterogeneity across observations.

Lastly, cost estimates reported here should be interpreted with caution. Though this method is commonly used in policing studies to estimate savings, it does not capture a number of other costs associated with technology adoption. Hardware procurement, training, and operations migration are just a few common factors that require financial and time investment to realize new technology. These costs are not captured here. Estimates on the cost of wireless-enabled land mobile radios cannot be reported given the nondisclosure agreement between the research team, communications vendor for this study, and the National Institute of Justice which funded the study. 
Despite this limitation, estimates provided in this study demonstrate the potential value of this innovative technology, as well as the potential officer efficiency gains that could be achieved to maximize officer time while on duty. This study is a unique contribution to the literature that is largely absent any examinations of police mobile radio use. Rigorous spatial analysis techniques were incorporated to explore an elusive question relating to the potential benefits of wireless radio programming technology. Given the practical nature of the research question, this study helps to bridge the gap between academics and practitioners by generating findings that can be used by police administrators in their policy decisions relative to communications technology. 


\section{References}

Blumstein, A. 2018. "Science and technology and the President's Crime Commission." Criminology \& Public Policy, 17(2): 271-282.

Braga, A. A., Flynn, E. A., Kelling, G. L., and Cole, C. M. 2011. Moving the Work of Criminal Investigators Towards Crime Control. Washington, DC: U.S. Department of Justice, National Institute of Justice.

Carter, J. G. and Grommon, E. L. 2014. "Wireless broadband for municipal police: Evaluating clearance times of calls for service." Police Quarterly, 17(3): 226-249.

Choi, K. S., Librett, M., and Collins, T. J. 2014. "An empirical evaluation: Gunshot detection system and its effectiveness on police practices." Police Practice and Research, 15(1): 48-61.

Federal Communications Commission. 2006. FCC Narrowbanding Mandate: A Public Safety Guide for Compliance. Washington, DC. Retrieved from https://transition.fcc.gov/pshs/docs/clearinghouse/guidelines/Narrowbanding_Booklet.pdf

Federal Communications Commission (FCC). 2015. 2015 Broadband Progress Report. Washington, DC. Retrieved from https://www.fcc.gov/reportsresearch/reports/broadband-progress-reports/2015-broadband-progress-report

Federal Communications Commission (FCC). 2018. Issues of Software Defined Radio Implementations for Public Safety. Washington, DC. Retrieved from https://www.fcc.gov/general/issues-software-defined-radio-implementations-publicsafety

Greasley, A., and Smith, C. M. 2017. "Using activity-based costing and simulation to reduce cost at a police communications center." Policing: An International Journal, 40(2): 426-441.

Hatry, H. (2014). Transforming Performance Measurement for the 21st Century. Washington, DC: The Urban Institute.

Ioimo, R. E., and Aronson, J. E. 2004. "Police field mobile computing: Applying the theory of task-technology fit." Police Quarterly, 7(4): 403-428.

Irvin-Erickson, Y., La Vigne, N., Levine, N., Tiry, E., and Bieler, S. 2017. "What does gunshot detection technology tell us about gun violence?" Applied Geography, 86: 262-273.

Kirk, R. (1995). Experimental Design: Procedures for the Behavioral Sciences. 3rd Edition. Pacific Grove, CA: Brooks/Cole. 
Koper, C. S., Lum, C., and Willis, J. J. 2014. “Optimizing the use of technology in policing: Results and implications from a multi-site study of the social, organizational, and behavioral aspects of implementing police technologies." Policing: A Journal of Policy and Practice, 8(2): 212-221.

Koper, C. S., Taylor, B. G. and Kubu, B. E. 2009. Law Enforcement Technology Needs Assessment: Future Technologies to Address the Operational Needs of Law Enforcement. Washington, DC: Police Executive Research Forum and the Lockheed Martin Corporation.

Koper, C. S., Taylor, B., and Woods, D. 2013. "A randomized test of initial and residual deterrence from directed patrol and use of license plate readers at crime hot spots." Journal of Experimental Criminology, 9(2): 213-244.

Kumbhar, A., Koohifar, F., Güvenç I., and Mueller, B. 2017. "A survey on legacy and emerging technologies for public safety communications." IEEE Communications Surveys \& Tutorials, 19(1): 97-124.

Lauria, D. T. 2007. “Cost-benefits analysis of Tacoma's assigned vehicle program.” Police Quarterly, 10(2): 192-217.

Lum, C., Hibdon, J., Cave, B., Koper, C. S., and Merola, L. 2011. "License plate reader (LPR) police patrols in crime hot spots: An experimental evaluation in two adjacent jurisdictions." Journal of Experimental Criminology, 7(4): 321-345.

Lum, C., Koper, C. S., Merola, L. M., Scherer, A., and Reioux, A. 2015. Existing and Ongoing Body Worn Camera Research: Knowledge Gaps and Opportunities. Report for the Laura and John Arnold Foundation. Fairfax, VA: Center for Evidence-Based Crime Policy, George Mason University.

Lum, C., Koper, C. S., and Willis, J. J. 2017. "Understanding the limits of technology's impact on police effectiveness.” Police Quarterly, 20(2): 135-163.

Merwaday, A., Tuncer, A., Kumbhar, A., and Guvenc, I. 2016. "Improved throughput coverage in natural disasters: Unmanned aerial base stations for public-safety communications." IEEE Vehicular Technology Magazine, 11(4): 53-60.

Mohler, G. O., Short, M. B., Malinowski, S., Johnson, M., Tita, G. E., Bertozzi, A., and Brantingham, P. J. 2015. "Randomized controlled field trials of predictive policing." Journal of the American Statistical Association, 110(512): 1399-1411. 
National Governors Association. 2009. Advancing Public Safety Interoperable Communications: Recent State Actions. Issue Brief. Retrieved from https://www.nga.org/files/live/sites/NGA/files/pdf/0906ADVANCINGPUBLICSAFETY .PDF

National Institute of Justice. 2009. Over-the-Air (OTA) Communications Improvements for Police Departments. U.S. Department of Justice. Washington, DC. Retrieved from https://www.ncjrs.gov/pdffiles1/nij/224791.pdf

President's Task Force on 21st Century Policing. 2015. Final Report of the President's Task Force on 21st Century Policing. Washington, DC: Office of Community Oriented Policing Services.

Rutgers, M. R., and van der Meer, H. 2010. "The origins and restriction of efficiency in public administration: Regaining efficiency as the core value of public administration." Administration \& Society, 42(7): 755-779.

Schaenman, P., and Horvath, A. 2013. Opportunities for Police Cost Savings Without Sacrificing Service Quality: Reducing Fuel Consumption. Washington, DC: The Urban Institute.

Sharp, D. S., Cackov, N., Laskovic, N., Shao, Q., and Trajkovic, L. 2004. “Analysis of public safety traffic on trunked land mobile radio systems." IEEE Journal on Selected Areas in Communications, 22(7): 1197-1205.

Taylor, B., Koper, C. S., and Woods, D. 2012. "Combating auto theft in Arizona: A randomized experiment with license plate recognition technology." Criminal Justice Review, 37(1): 24-50.

Thomspon, B. 2006. Foundations of Behavioral Statistics: An Insight-Based Approach. New York, NY: Guilford.

U.S. Department of Homeland Security. 2014. Interoperability Continuum. SAFECOM Program. Washington, DC. Retrieved from http://www.safecomprogram.gov/oec/interoperability_continuum_brochure_2.pdf

U.S. Department of Transportation. 2015. 2015 Status of the Nation's Highways, Bridges, and Transit: Conditions \& Performance. Report to Congress. Retrieved from https://www.fhwa.dot.gov/policy/2015cpr/pdfs/littlebook.pdf

Wang, F., and Xu, Y. 2011. "Estimating O-D travel time matrix by Google Maps API: Implementation, advantages, and implications.” Annals of GIS, 17(4): 199-209. 
White, M. D. 2014. Police Officer Body-Worn Cameras: Assessing the Evidence. Washington, DC: Office of Community Oriented Policing Services.

White, M. D., and Katz, C. M. 2013. "Policing convenience store crime: Lessons learned from the Glendale, Arizona smart policing initiative." Police Quarterly, 16(3): 305-322.

Zhang, S. X., and Benson, T. D. 1997. "Cost-effectiveness and officer morale of a personally assigned patrol vehicle program: A comparative analysis.” Policing: An International Journal of Police Strategies \& Management, 20(4): 749-765.

Zhang, D., Chow, C.Y., Liu, A., Zhang, X., Ding, Q., and Li, Q. 2017. “Efficient evaluation of shortest travel-time path queries through spatial mashups." Geoinformatica, 22(3): Online First. https://doi.org/10.1007/s10707-016-0288-4

Zhao, J. S., Scheider, M. C., and Thurman, Q. 2003. "A national evaluation of the effect of COPS grants on police productivity (arrests) 1995-1999." Police Quarterly, 6(4): 387409. 
Tables and Figures

Table 1. Wireless Broadband Services in North Carolina

\begin{tabular}{|c|c|c|c|}
\hline Code & Description & $\begin{array}{l}\text { Minimum Download } \\
\text { Speed }\end{array}$ & $\begin{array}{c}\text { Maximum } \\
\text { Download Speed }\end{array}$ \\
\hline 1 & $\begin{array}{c}\text { Cellular } \\
(824-849 \mathrm{MHz})\end{array}$ & $768 \mathrm{kbps}-1.5 \mathrm{mbps}$ & $768 \mathrm{kbps}-1.5 \mathrm{mbps}$ \\
\hline \multirow{2}{*}{$\begin{array}{l}2 \\
3\end{array}$} & $700 \mathrm{MHz}$ & $10 \mathrm{mbps}-25 \mathrm{mbps} *$ & $10 \mathrm{mbps}-25 \mathrm{mbps} *$ \\
\hline & $\begin{array}{l}\text { Broadband Personal Communications } \\
\qquad(1825-1915 \mathrm{MHz})\end{array}$ & $768 \mathrm{kbps}-1.5 \mathrm{mbps}$ & $10 \mathrm{mbps}-25 \mathrm{mbps} *$ \\
\hline 4 & $\begin{array}{l}\text { Advanced Wireless Services } \\
\qquad(1710-1755 \mathrm{MHz})\end{array}$ & $768 \mathrm{kbps}-1.5 \mathrm{mbps}$ & 10 mbps -25 mbps* \\
\hline 5 & $\begin{array}{c}\text { Broadband Radio Service/Education } \\
\text { Broadband Service } \\
(2496-2690 \mathrm{MHz})\end{array}$ & 3 mbps - 6 mbps* & 10 mbps -25 mbps* \\
\hline 6 & $\begin{array}{c}\text { Unlicensed } \\
\text { (including TV "white spaces") }\end{array}$ & $768 \mathrm{kbps}-1.5 \mathrm{mbps}$ & $\begin{array}{l}50 \text { mbps }-100 \\
\text { mbps* }\end{array}$ \\
\hline 7 & $\begin{array}{l}\text { Specialized Mobile Radio Service } \\
\qquad(817-940 \mathrm{MHz})\end{array}$ & $1.5 \mathrm{mbps}-3 \mathrm{mbps}$ & $10 \mathrm{mbps}-25 \mathrm{mbps} *$ \\
\hline 8 & $\begin{array}{l}\text { Wireless Communications Service } \\
\qquad(2305-2360 \mathrm{MHz})\end{array}$ & 3 mbps - 6 mbps* & 10 mbps - 25 mbps* \\
\hline 9 & Satellite (2 GHz) & 10 mbps - 25 mbps* & $10 \mathrm{mbps}-25 \mathrm{mbps} *$ \\
\hline
\end{tabular}

Table 2. Summary of Distance Variables

\begin{tabular}{lccccc}
\hline \multicolumn{1}{c}{ Variable } & Mean & Standard Deviation & Median & Minimum & Maximum \\
\hline Miles to Radio & 35.69 & 20.52 & 33.57 & 0.01 & 110.28 \\
Miles to Broadband & $<0.01$ & 0.001 & $<0.01$ & 0.00 & 0.76 \\
Miles Saved & 35.68 & 20.52 & 33.57 & 0.01 & 110.28 \\
\hline
\end{tabular}


Table 3. Average Miles saved across Troops

\begin{tabular}{|c|c|c|}
\hline Troop & Mean (S.D.) & $\mathbf{N}$ \\
\hline $\mathrm{A}$ & $46.70(21.90)$ & 61049 \\
\hline B & $42.39(16.13)$ & 91621 \\
\hline $\mathrm{C}$ & $33.64(22.05)$ & 92916 \\
\hline $\mathrm{D}$ & $27.06(15.28)$ & 63217 \\
\hline $\mathrm{E}$ & $32.46(16.58)$ & 74358 \\
\hline $\mathrm{F}$ & $29.92(16.30)$ & 71591 \\
\hline $\mathrm{G}$ & $35.76(23.37)$ & 119066 \\
\hline $\mathrm{H}$ & $36.97(21.88)$ & 71822 \\
\hline Total & $35.69(20.52)$ & 645640 \\
\hline $\mathrm{F}(p)^{*}$ & $7277.96(0.00)$ & \\
\hline Effect Size, ETA ${ }^{2 * *}$ & 0.07 & \\
\hline Bartlett's $X^{2}(p)$ & $35000(0.00)$ & \\
\hline Kruskal Wallis $(p)^{* * *}$ & $47854.15(0.00)$ & \\
\hline $\begin{array}{l}* d f=7,645632 \\
* * E T A^{2} \text { is interpreted as } t \\
\text { sample. Guidelines for eff } \\
\text { 2006). } \\
* * * \text { Kruskal Wallis test ac }\end{array}$ & $\begin{array}{l}\text { nt of the dependent val } \\
0.01 \text { small; } 0.06 \text { medir }\end{array}$ & $\begin{array}{l}\text { by the effect in the } \\
\text { 1995; Thompson, }\end{array}$ \\
\hline
\end{tabular}

Table 4. Average Miles saved across Road Types

\begin{tabular}{lcc}
\hline Road Type & Mean (S.D.) & $\mathbf{N}$ \\
\hline Interstate Highways & $26.36(15.64)$ & 3923 \\
U.S. Highways & $38.25(20.87)$ & 14266 \\
N.C. State Roadways & $37.82(19.52)$ & 14552 \\
Secondary Roadways & $35.72(19.93)$ & 180988 \\
Local Roadways & $35.60(20.79)$ & 431911 \\
Total & $35.69(20.52)$ & 645640 \\
\hline $\mathrm{F}(p)^{*}$ & $299.87(0.00)$ \\
Effect Size, ETA ${ }^{2 * *}$ & 0.002 \\
Bartlett's X $(p)$ & $1030(0.00)$ \\
Kruskal Wallis $(p){ }^{* * *}$ & $1310.68(0.00)$ \\
\hline$* d f=4,645635$ & & \\
$* *$ ETA ${ }^{2}$ is interpreted as the percent of the dependent variable accounted for by the effect in the \\
sample. Guidelines for effect size: 0.01 small; 0.06 medium; 0.14 large (Kirk, 1995; Thompson, \\
2006). \\
$* * *$ Kruskal Wallis test accounts for ties within the data.
\end{tabular}


Table 5. Average Miles saved across Troops, by Road Type

\begin{tabular}{|c|c|c|c|c|c|c|c|c|c|c|}
\hline \multirow{2}{*}{ Troop } & \multicolumn{2}{|c|}{ Interstate Highways } & \multicolumn{2}{|c|}{ U.S. Highways } & \multicolumn{2}{|c|}{ N.C. State Roadways } & \multicolumn{2}{|c|}{ Secondary Roadways } & \multicolumn{2}{|c|}{ Local Roadways } \\
\hline & $\begin{array}{l}\text { Mean } \\
\text { (S.D.) }\end{array}$ & $\mathbf{N}$ & Mean (S.D.) & $\mathbf{N}$ & Mean (S.D.) & $\mathbf{N}$ & $\begin{array}{l}\text { Mean } \\
\text { (S.D.) }\end{array}$ & $\mathbf{N}$ & $\begin{array}{l}\text { Mean } \\
\text { (S.D.) }\end{array}$ & $\mathbf{N}$ \\
\hline $\mathrm{A}^{\wedge}$ & na & na & $41.28(22.38)$ & 2066 & $43.17(21.46)$ & 2181 & $\begin{array}{c}44.75 \\
(20.62)\end{array}$ & 18116 & $\begin{array}{c}48.10 \\
(22.34)\end{array}$ & 38686 \\
\hline B & $38.89(9.43)$ & 537 & $41.29(15.98)$ & 2348 & $38.56(17.49)$ & 3122 & $\begin{array}{c}40.83 \\
(16.36)\end{array}$ & 23223 & $\begin{array}{c}43.23 \\
(15.94)\end{array}$ & 62391 \\
\hline $\mathrm{C}$ & $\begin{array}{c}26.82 \\
(20.03)\end{array}$ & 685 & $36.91(21.44)$ & 2358 & $42.64(21.19)$ & 2145 & $\begin{array}{c}37.37 \\
(21.17)\end{array}$ & 27494 & $\begin{array}{c}31.57 \\
(22.20)\end{array}$ & 60234 \\
\hline D & $\begin{array}{c}19.66 \\
(10.23)\end{array}$ & 799 & $32.86(15.27)$ & 1467 & $29.16(12.20)$ & 1234 & $\begin{array}{c}26.70 \\
(13.47)\end{array}$ & 22332 & $\begin{array}{c}27.14 \\
(16.35)\end{array}$ & 37385 \\
\hline $\mathrm{E}$ & $\begin{array}{c}31.47 \\
(17.91)\end{array}$ & 493 & $31.25(17.58)$ & 1116 & $35.44(17.00)$ & 1784 & $\begin{array}{c}33.10 \\
(16.80)\end{array}$ & 24109 & $\begin{array}{c}32.06 \\
(16.39)\end{array}$ & 46856 \\
\hline $\mathrm{F}$ & $\begin{array}{c}31.31 \\
(15.40)\end{array}$ & 382 & $29.96(15.48)$ & 1114 & $31.37(17.43)$ & 1366 & $\begin{array}{c}28.66 \\
(16.53)\end{array}$ & 22702 & $\begin{array}{c}30.48 \\
(16.15)\end{array}$ & 46027 \\
\hline G & $\begin{array}{c}17.92 \\
(10.35)\end{array}$ & 623 & $40.79(25.60)$ & 2519 & $36.11(21.99)$ & 1291 & $\begin{array}{c}35.44 \\
(23.35)\end{array}$ & 22908 & $\begin{array}{c}35.82 \\
(23.33)\end{array}$ & 91725 \\
\hline $\mathrm{H}$ & $\begin{array}{c}24.31 \\
(11.20)\end{array}$ & 404 & $44.72(21.80)$ & 1278 & $38.94(20.64)$ & 1429 & $\begin{array}{c}40.84 \\
(22.62)\end{array}$ & 20104 & $\begin{array}{c}35.21 \\
(21.39)\end{array}$ & 48607 \\
\hline Total & $\begin{array}{c}26.36 \\
(15.64)\end{array}$ & 3923 & $38.25(20.87)$ & 14266 & $37.82(19.52)$ & 14552 & $\begin{array}{c}35.72 \\
(19.93)\end{array}$ & 180988 & $\begin{array}{c}35.60 \\
(20.79)\end{array}$ & 431911 \\
\hline $\mathrm{F}(p)^{*}$ & & $\begin{array}{c}159.64 \\
(0.00)\end{array}$ & $\begin{array}{l}99.10 \\
(0.00)\end{array}$ & & $\begin{array}{c}110.10 \\
(0.00)\end{array}$ & & $\begin{array}{r}227 \\
(0 .\end{array}$ & & $\begin{array}{r}54 \\
(0\end{array}$ & \\
\hline Effect $S$ & $\mathrm{ze}, \mathrm{ETA}^{2 * *}$ & 0.20 & 0.05 & & 0.05 & & & & & \\
\hline Bartlett' & $\mathrm{X}^{2}(p)$ & $\begin{array}{c}691.46 \\
(0.00)\end{array}$ & $\begin{array}{c}997.25 \\
(0.00)\end{array}$ & & $\begin{array}{c}674.32 \\
(0.00)\end{array}$ & & & & & \\
\hline Kruskal & Wallis $(p)^{* * *}$ & $\begin{array}{c}815.43 \\
(0.00)\end{array}$ & $\begin{array}{c}634.63 \\
(0.00)\end{array}$ & & $\begin{array}{c}668.48 \\
(0.00)\end{array}$ & & $\begin{array}{r}146 \\
(0\end{array}$ & & $\begin{array}{r}359 \\
(0\end{array}$ & \\
\hline $\begin{array}{l}{ }^{\wedge} \text { No Int } \\
* d f=6, \\
* * E T A^{2} \\
0.14 \text { lar } \\
* * * \text { Kru }\end{array}$ & $\begin{array}{l}\text { ate Highways } \\
6 ; 7,14258 ; 7 \\
\text { nterpreted as } \\
\text { Kirk, 1995; T } \\
\text { Wallis test ac }\end{array}$ & $\begin{array}{l}\text { ontained } \\
44 ; 7,18 \\
\text { rcent of } \\
\text { son, } 200\end{array}$ & $\begin{array}{l}\text { n Troop A. } \\
7,1805 \\
\text { ependent variable } \\
\text { in the data. }\end{array}$ & 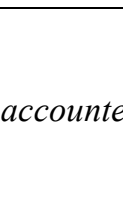 & (c) & & Taidalin & . & 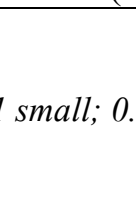 & ium; \\
\hline
\end{tabular}


Table 6. Average Time and Cost Savings by NCSHP Troop*

\begin{tabular}{cccccccccc}
\hline Troop & Troopers & $\begin{array}{c}\text { Average } \\
\text { Per-Mile } \\
\text { Travel } \\
\text { Time }\end{array}$ & $\begin{array}{c}\text { Avg Miles } \\
\text { Saved } \\
\text { (mins/mile }\end{array}$ & $\begin{array}{c}\text { Avg Travel } \\
\text { Time Saved } \\
\text { (Mins) }\end{array}$ & $\begin{array}{c}\text { Total Miles } \\
\text { Saved }\end{array}$ & $\begin{array}{c}\text { Total Time } \\
\text { Saved (Mins) }\end{array}$ & $\begin{array}{c}\text { Personnel } \\
\text { Cost Savings** }\end{array}$ & $\begin{array}{c}\text { Vehicle } \\
\text { Cost } \\
\text { Savings*** }\end{array}$ & $\begin{array}{c}\text { Total Money } \\
\text { Saved }\end{array}$ \\
\hline A & 190 & 1.26 & 46.7 & 58.84 & $17,746.00$ & $22,359.96$ & $\$ 10,934.02$ & $\$ 10,203.95$ & $\$ 21,137.97$ \\
B & 256 & 1.37 & 42.39 & 58.07 & $21,703.68$ & $29,734.04$ & $\$ 14,539.95$ & $\$ 12,479.62$ & $\$ 27,019.56$ \\
C & 273 & 1.16 & 33.64 & 39.02 & $18,367.44$ & $21,306.23$ & $\$ 10,418.75$ & $\$ 10,561.28$ & $\$ 20,980.02$ \\
D & 188 & 1.24 & 27.06 & 33.55 & $10,174.56$ & $12,616.45$ & $\$ 6,169.45$ & $\$ 5,850.37$ & $\$ 12,019.82$ \\
E & 197 & 1.29 & 32.46 & 41.87 & $12,789.24$ & $16,498.12$ & $\$ 8,067.58$ & $\$ 7,353.81$ & $\$ 15,421.39$ \\
F & 174 & 1.38 & 29.92 & 41.29 & $10,412.16$ & $14,368.78$ & $\$ 7,026.33$ & $\$ 5,986.99$ & $\$ 13,013.33$ \\
G & 199 & 1.20 & 35.76 & 42.91 & $14,232.48$ & $17,078.98$ & $\$ 8,351.62$ & $\$ 8,183.68$ & $\$ 16,535.30$ \\
H & 187 & 1.20 & 36.97 & 44.36 & $13,826.78$ & $16,592.14$ & $\$ 8,113.55$ & $\$ 7,950.40$ & $\$ 16,063.953$ \\
Total & 1,664 & - & 284.9 & 359.93 & $119,252.34$ & $150,554.70$ & $\$ 73,621.25$ & $\$ 68,570.10$ & $\$ 142,191.34$ \\
\hline
\end{tabular}

*Calculations reflect a minimum of 2 programming trips per year, thus total miles and total time saved calculations are multiplied by 2.

**Personnel cost savings were calculated using a per-minute rate (\$.489) derived from NCSHP trooper salary and U.S. Office of Personnel Management time allocations for a work week that was then multiplied by average travel time saved.

***Vehicle cost savings were calculated based on the General Services Administration per-mile cost rate (\$.575/mile) that was then multiplied by the total miles saved. 
Figure 1. North Carolina Highway Patrol Troop Boundaries, Radio Maintenance Site Locations, and Road Types

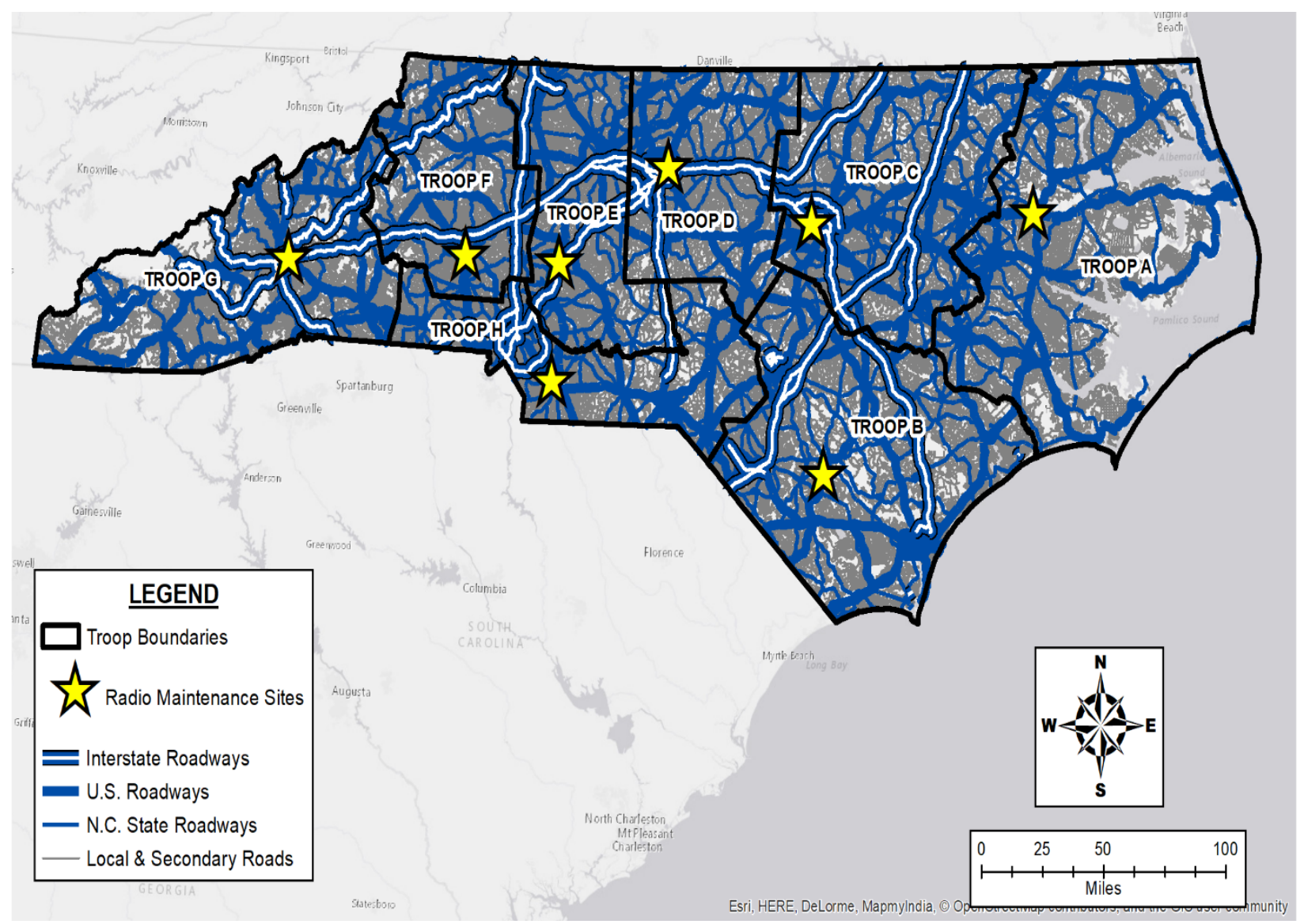


Figure 2. Officer Origin Points

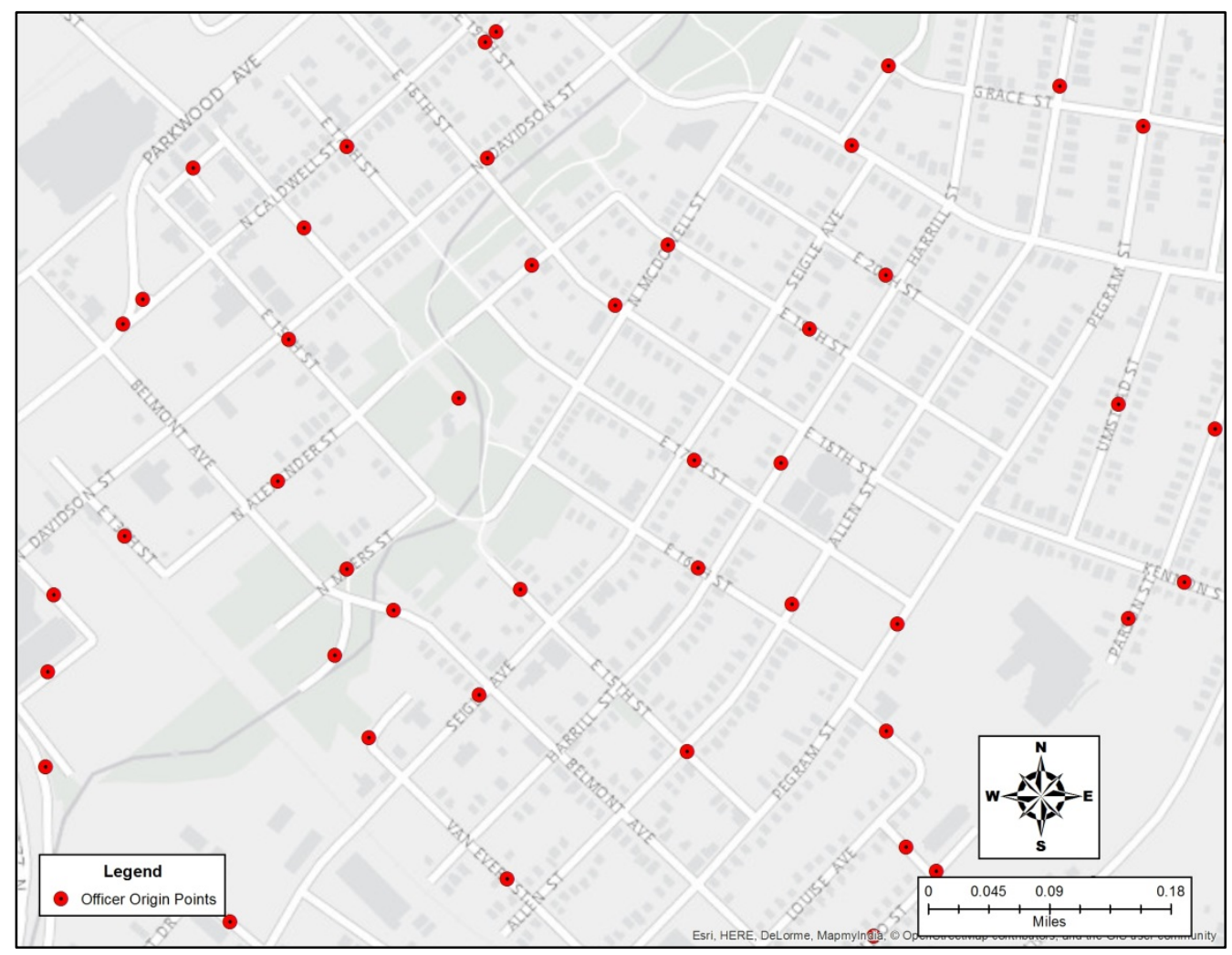

